\title{
CIÊNCIA, TECNOLOGIA E SOCIEDADE: FORMAÇÃO DE PROFESSORES E APROXIMAÇÃO UNIVERSIDADE-ESCOLA
}

\author{
Science, Technology and Society: Teacher Education and university-school \\ approximation
}

\author{
Krisnayne Santos Ribeiro* \\ Dayane Ferreira Santos** \\ Christiana Andréa Vianna Prudêncio ${ }^{* * *}$
}

Resumo: A formação do professor de ciências é uma preocupação constante no âmbito educacional. Alguns estudos apontam que as investigações sobre a formação destes profissionais, quando atrelada aos preceitos da Educação CTS (Ciência, Tecnologia e Sociedade), concentram-se na análise de concepções. Mas, como as ações formativas CTS têm desenvolvido o diálogo e a integração entre comunidade científica e escola? Para responder a esse questionamento mapeamos os trabalhos que articulam Educação CTS à formação de professores de ciências por meio de ações formativas desenvolvidas em disciplinas, eixo temático, grupo de pesquisa, projetos/programas e cursos de formação, no período de 2014 a 2019. Realizamos buscas em bases de dados de periódicos e nas atas de três edições do Encontro Nacional de Pesquisa em Ensino de Ciências (ENPEC). Esses estudos foram descritos e analisados com base na Análise Textual Discursiva (ATD) e as categorias de análise dizem respeito às características das ações formativas CTS e às interlocuções entre universidade e escola. Percebemos que as ações formativas acontecem principalmente nas disciplinas da formação inicial, mas não conseguem sozinhas fomentar relações estreitas entre academia e escola. Ao mesmo tempo, programas de formação de professores têm sido importantes para a interação entre profissionais da escola e universidade, além disso, nas discussões surgem espaços com potencialidade para o desenvolvimento de formações com viés CTS. Compreendemos que as ações precisam ser pensadas como uma rede de iniciativas que integre diferentes atores, fomentando discussões sobre CTS e autonomia dos profissionais envolvidos.

Palavras-chave: Educação CTS. Formação Docente Crítica. Educação Progressista.

Abstract: Science teacher education is a constant concern in the educational field. Some studies indicate that investigations on the training of these professionals, when linked to the precepts

\footnotetext{
* Licenciada em Ciências Biológicas pela Universidade Estadual de Santa Cruz - UESC (2018) e mestranda em Educação em Ciências e Matemática, pela mesma universidade. Orcid: https://orcid.org/0000-0002-1164-1378. Email: krisnayne@hotmail.com.

** Licenciada em Ciências Biológicas pela Universidade Estadual de Santa Cruz - UESC (2018) e mestranda em Educação em Ciências e Matemática, pela mesma universidade. Orcid: https://orcid.org/0000-0002-8232-1638. E-mail: daday014@hotmail.com.

**** Mestre e doutora em Educação pela Universidade Federal de São Carlos/SP - UFSCar. Professora adjunta da área de ensino de Biologia da Universidade Estadual de Santa Cruz - UESC. Orcid: http://orcid.org/0000-00024571-2090. E-mail: cavprudencio@uesc.br.
} 
of STS Education (Science, Technology and Society), focus on the analysis of conceptions. But how have STS training actions developed dialogue and integration between the scientific community and the school? To answer this question were mapped the works that articulate STS Education to the formation of science teachers through formative actions developed in disciplines, thematic axis, research group, projects / programs and training courses, from 2014 to 2019. Were conducted searches in journal databases and in the minutes of three editions of the Encontro Nacional de Pesquisa em Ensino de Ciências (ENPEC), these studies were characterized and analyzed based on Discursive Textual Analysis (ATD) and the analysis categories concern the characteristics of the STS formative actions and the interlocutions between university and school. It was understood that the formative actions happen mainly in the subjects of initial formation, but they cannot alone foster close relations between academy and school. At the same time, teacher training programs have been important for the interaction between school and university professionals, and, in the discussions, spaces appear with potential for the development of STS bias training. We understand that actions need to be thought of as a network of initiatives that integrate different actors, fostering discussions about STS and autonomy of the professionals involved.

Keywords: STS Education. Critical Teacher Formation. Progressive Education.

\section{Introdução}

A formação do professor como intelectual crítico é defendida pelas perspectivas educacionais progressistas, preocupadas com a transformação social e a emancipação dos sujeitos, dentre as quais podemos citar a Pedagogia Freireana, Pedagogia Histórico-Crítica e a Educação CTS (Ciência, Tecnologia e Sociedade) (SOUZA DE FREITAS; QUEIRÓS, 2019).

A Educação CTS defende a formação cidadã crítica do educando e a consciência sobre direitos e deveres, como também autonomia diante das problemáticas sociais envolvidas com seu contexto de vida. Nessa perspectiva educacional as discussões sobre Ciência e Tecnologia (CT) a partir de temáticas sociais são o cerne do ensino (AULER, 2003). Nessa proposta o papel do professor como cidadão e educador compreende a consciência sobre as influências da CT na sociedade, além do ensino que problematize tais conhecimentos.

Auler (2002) defende que os cursos de formação inicial e continuada de professores necessitam, por exemplo, abordar questões referentes a não neutralidade científica e as incongruências do modelo científico positivista, discutir o modelo de decisões tecnocráticas e refletir a respeito das compreensões reducionistas sobre CT. O entendimento das concepções sobre CT manifestadas pelos professores é compartilhado por pesquisadores de diferentes países. Pensando no desenvolvimento de ações voltadas para a formação desses profissionais Auler e Delizoicov (2006) investigam as compreensões de professores sobre as inter-relações entre Ciência, Tecnologia e Sociedade e identificam que suas concepções tendem a ser equivocadas e simplistas, sugerindo, nesse caso, que outras pesquisas investiguem os aspectos envolvidos com essas visões.

Desde então, as pesquisas sobre formação de professores na Educação CTS se concentraram na interpretação dessas concepções. Selli Deconto, Cavalcanti e Ostermann (2016) afirmam que as ideias de professores e/ou licenciandos sobre CT costumam ser guiadas por ideias reducionistas e de senso comum, mas defendem que processos formativos têm o potencial de proporcionar mudanças que podem influenciar nas práticas educacionais.

Apesar desse reconhecimento alguns pesquisadores sinalizam que há poucas iniciativas nessa direção, e a maioria dos estudos que articulam Educação CTS e formação de professores 
concentram-se na compreensão das concepções docentes sobre CT (STRIEDER et al., 2016; LACERDA; SANTOS; QUEIRÓS, 2017; SANTOS; VALE; SILVA, 2017; PENHA; MACIEL, 2019). Além disso, apontam a necessidade do desenvolvimento de processos formativos integradores que consigam aproximar a academia da comunidade escolar (STRIEDER et al., 2016; LACERDA; SANTOS; QUEIRÓS, 2017).

Diante dessas considerações e da necessidade de um modelo de formação preocupado com a preparação intelectual crítica e transformadora (SOUZA DE FREITAS; QUEIRÓS, 2019), questionamos qual o potencial das ações formativas CTS para o diálogo e integração entre comunidade científica e escolar. Nesse sentido, o objetivo desse trabalho é mapear estudos que apresentem ações CTS de formação inicial ou continuada de professores de ciências, a fim de compreender tanto os aspectos enfatizados nessas atividades quanto às possibilidades do trabalho colaborativo entre comunidade acadêmica e comunidade escolar.

\section{Educação CTS e concepções de professores de ciências sobre CT}

O cenário pós II Guerra Mundial foi marcado pela disputa científica e tecnológica entre Estados Unidos e a antiga União Soviética, uma "guerra fria" caracterizada por disputas desenfreadas de poder, que provocaram, por exemplo, desastres ambientais e acidentes nucleares. E suscitaram questionamentos sobre as relações CTS, que contradiziam as visões tradicionalistas sobre CT. No final da década de 1960 e início de 1970 surge o Movimento CTS, que na Europa estava diretamente atrelado às pesquisas acadêmicas sobre as influências da Sociologia na Ciência, e nos EUA estava vinculado às reivindicações sociais. De maneira geral, questionou a neutralidade da CT, a visão reducionista da Tecnologia como produto da Ciência e o modelo de decisões tecnocráticas. Tais discussões tomaram diferentes rumos e influenciaram políticas públicas, pesquisas acadêmicas e a Educação (CEREZO, 1998).

No âmbito educacional, o foco das discussões são os conhecimentos de CT historicamente construídos, acompanhada de questionamentos sobre a natureza da ciência, o desenvolvimento da CT e relações de poder atreladas ao domínio desses saberes. A partir desse delineamento, são desenvolvidos currículos de Ciências que questionem a CT e suas implicações na sociedade (AIKENHEAD, 1994). Para tanto, os professores necessitam reconhecer a relevância dessas questões, assumindo seu papel social na formação cidadã de estudantes, (re)estruturando concepções pedagógicas (SANTOS; MORTIMER, 2000; 2001).

Esse processo exige indagações sobre CT para a consolidação de concepções profissionais que possibilitem o desenvolvimento de práticas educacionais vinculadas a Educação CTS. Essa discussão coloca a formação do professor como um dos pilares para a efetivação do ensino CTS, e nesse aspecto é relevante considerar também que a comunidade acadêmica tem grande responsabilidade na preparação destes docentes (MARTINS, 2002).

Diversos autores buscaram entender as visões sobre CT. No Canadá, Aikenhead e Ryan (1992) desenvolveram o Views on Science-Technology-Society (VOSTS), ferramenta que tece questionamentos sobre as relações CTS, permitindo o estudo de opiniões sobre CT, influências sociais da CT, conhecimento escolar, perfis dos cientistas e reflexões sobre natureza da ciência. $\mathrm{Na}$ Espanha, também foi desenvolvido o Cuestionario de Opiniones sobre Ciencia Tecnología y Sociedad (COCTS) instrumento que avalia crenças e posicionamentos sobre CT (ALONSO; ACEVEDO DÍAZ; MANASSERO MAS, 2006). Tais inquietações promoveram o desenvolvimento de programas internacionais voltados para as compreensões sobre CTS. Diferentes estudos, em contextos distintos, que utilizam essas ferramentas para compreender as concepções de professores e estudantes sobre CT foram e continuam sendo importantes para a estruturação de ações formativas CTS (MIRANDA et al., 2017; MÜNCHEN; ADAIME, 2019). 
Assim, tornaram-se comuns no ensino de ciências as investigações das concepções de professores sobre CTS, que apontam que elas não raro se fundamentavam em compreensões ingênuas, pois na maioria das vezes reproduziam mitos sobre CT. Auler e Delizoicov (2006) reconhecem a necessidade da elaboração de processos formativos para a (re)construção de ideias, pois percebem dificuldades a respeito da articulação de questões políticas a CT.

É nesse contexto que crescem as indagações sobre a formação do professor a partir dos preceitos CTS, com foco na preparação de profissionais críticos quanto às questões de CT e suas implicações políticas, econômicas, sociais e didático-pedagógicas. No entanto, ressaltamos que os estudos CTS são plurais, em suas ênfases e compreensões (STRIEDER, 2012), e essa heterogeneidade possivelmente interfere nas formações docentes. Na Educação CTS é importante que as ações formativas consigam ser desenvolvidas a partir de seus parâmetros e propósitos, que direcionam aspectos gerais que deveriam ser abordados na formação do professor. É importante propiciar percepções, questionamentos e compromisso social a respeito das relações CTS. Assim, a racionalidade técnica, desenvolvimento tecnológico e a participação social necessitam ser trabalhados nesse processo (STRIEDER; KAWAMURA, 2017).

No que diz respeito ao estudante, a autonomia e pensamento crítico defendidos pela Educação CTS devem ser também desenvolvidos nas formações iniciais e continuadas dos professores para que consigam comportar-se como cidadãos críticos diante da realidade educacional de seu contexto (PRUDÊNCIO, 2013). Sobre essa formação crítico-autônoma é relevante considerar que a dimensão da participação social raramente é abordada nos estudos CTS, prejudicando o engajamento político-social (ROSA; STRIEDER, 2019). Mas as pesquisas sobre formação de professores nessa área ainda são tímidas quando comparadas, por exemplo, às discussões acerca das intervenções didáticas (MORENO RODRÍGUEZ; DEL PINO, 2019a). Outras revisões de literatura sugerem que as ações de formação precisam aproximar a academia do universo escolar, fomentando pesquisas e práticas preocupadas com a realidade das escolas (STRIEDER et al., 2016; LACERDA; SANTOS; QUEIRÓS, 2017).

\section{A necessária aproximação entre universidade e escola}

Como vimos a formação do professor a partir da Educação CTS pretende construir novas significações da docência, mudar concepções preconcebidas sobre as relações entre Ciência, Tecnologia e Sociedade, bem como visões acerca do papel do professor nesse cenário. Tais saberes e comportamentos dialogam com as necessidades formativas apontadas por Carvalho e Gil-Pérez (2011) que envolvem ruptura de visões simplistas, conhecimentos sobre as relações CTS, questionamentos sobre a Ciência, implicações sociais do conhecimento científico e importância do trabalho com situações problemas.

A revolução pretendida na profissionalidade do professor de Ciências necessita ser pensada pelas universidades e escolas da Educação Básica. Professores quando trabalham em colaboração com formadores universitários podem construir relações que articulam teoria e prática, e produzir novos conhecimentos, além daqueles desenvolvidos no exercício da docência. Assim, é necessário que as escolas cada vez mais se tornem espaços onde os professores consigam também aprender e não apenas ensinar. Essa dinâmica é capaz de transformar sistemas escolares, pois a aprendizagem dos estudantes depende do que os professores fazem e sabem (MARCELO GARCÍA; VAILLANT, 2011).

Para entender a relação universidade-escola é necessário considerar o espaço que Fiorentini (2013) nomeia de comunidade fronteiriça, em que as duas comunidades interagem e podem aproximar-se por meio do diálogo sobre o processo de ensino e aprendizagem da prática docente. A imprescindibilidade da parceria entre universidade e escola é reconhecida pelos 
especialistas em Educação Científica Crítica, que defendem a formação cidadã para pensar e lidar com as repercussões dos conhecimentos de CT. De acordo com eles, a sinergia universidade-escola é importante para que a escola seja encarada como espaço de produção de conhecimento e agente fundamental na formação de professores (SANTOS et al., 2019).

De acordo Barolli e Villani (2015) as disputas envolvidas com as definições da formação de professores de ciências foram marcadas pela atuação limitada das instituições escolares, esses debates se iniciaram na renovação do ensino científico na década de 1950 e, desde então, abrangeram influências diversas, predomínio do método científico experimental, reproduções de propostas de ensino estrangeiras e maior envolvimento dos especialistas em ensino de ciências nas discussões sobre a crise generalizada do ensino básico. A colaboração universidade-escola e a autonomia escolar são fundamentais para que a escola abandone a condição de oprimida e "subverta a correlação de forças no campo da formação" (BAROLLI; VILLANI, 2015, p. 89), possibilitando uma nova dimensão participativa e de envolvimento nas decisões sobre diretrizes e currículos da formação de professores.

\section{Percurso metodológico}

As revisões recentes sobre Educação CTS e formação de professores analisam trabalhos publicados no intervalo de 2000 a 2017 (STRIEDER et al., 2016; LACERDA; SANTOS; QUEIRÓS, 2017; SANTOS; VALE; SILVA, 2017; PENHA; MACIEL, 2019). A partir da análise de seus focos de pesquisa e período de abrangência, decidimos investigar as pesquisas desenvolvidas nos últimos seis anos, 2014 a 2019, tendo em vista a reflexão das características dessas formações quando comparadas aos resultados de revisões anteriores.

Neste estudo qualitativo e com abordagem bibliográfica optamos por um enfoque metodológico diferente daqueles normalmente utilizados nas revisões de literatura mencionadas, efetuando buscas em diferentes bases de dados de periódicos e nas atas do maior evento da área de Educação em Ciências, o Encontro Nacional de Pesquisa em Educação em Ciências (ENPEC). Inicialmente mapeamos as ações formativas vinculadas à Educação CTS realizando buscas por artigos de periódicos das bases de dados do Scientific Electronic Library Online (SciELO), Red de Revistas Científicas de América Latina y el Caribe, España y Portugal (Redalyc), Portal de periódicos da Coordenação de Aperfeiçoamento de Pessoal de Nível Superior (Periódicos da CAPES) e Directory of Open Access Journals (DOAJ), com objetivo de associar os diferentes resultados e ampliar o campo de pesquisa.

Além disso, realizamos pesquisas nas atas do ENPEC, especificamente nas edições X, XI e XII, pois se encaixam no período de interesse. Nas bases de dados de periódicos empregamos equações de busca associando o termo de busca STS, sigla inglesa para CTS, aos termos Teacher Training, Teacher Formation e Teacher Education, expressões que remetem à formação de professores (STS AND teacher training; STS AND teacher formation e STS AND teacher education) associado a filtros de buscas referentes ao intervalo de tempo definido e idioma português e espanhol, no caso do Redalyc, selecionamos o campo de conhecimento Educação. É relevante enfatizar que os artigos do ano de 2019 são aqueles publicados até o mês de agosto e a opção pelos termos em inglês justifica-se pela preferência dos sistemas por esse idioma.

Nestas buscas, considerando a sobreposição de resultados, encontramos nas bases do SciELO, Redalyc, Periódicos da CAPES e DOAJ, 61 artigos relacionados ao tema de interesse. Nas atas do ENPEC o sistema de busca é simples e não há opções de filtragem como nas bases de dados de periódicos, por este motivo utilizamos o descritor CTS e, conforme apresentado na quadro 1 identificamos 268 trabalhos neste evento. 
Quadro 1 - Quantidade total de trabalhos sobre formação de professores com viés CTS e trabalhos empíricos selecionados

\begin{tabular}{|c|c|c|}
\hline Base de dados & $\begin{array}{c}\text { Busca inicial pelos descritores "CTS" (nas } \\
\text { atas do ENPEC), "STS AND teacher } \\
\text { training"; "STS AND teacher formation" e } \\
\text { "STS AND teacher education" (nas bases } \\
\text { de dados de periódicos) }\end{array}$ & $\begin{array}{c}\text { Pesquisas empíricas } \\
\text { sobre açóes formativas } \\
\text { CTS }\end{array}$ \\
$\begin{array}{c}\text { CTS partir da leitura do } \\
\text { (a) } \\
\text { resumo e metodologia) }\end{array}$ \\
\hline Anais do X ENPEC (2015) & 71 & 5 \\
\hline Anais do XI ENPEC (2017) & 112 & 8 \\
\hline Anais do XII ENPEC (2019) & 85 & 6 \\
\hline (2014-2019) & 61 & 29 \\
\hline TOTAL & $\mathbf{3 2 9}$ & $\mathbf{2 9}$ \\
\hline
\end{tabular}

Fonte: Elaborado pelas autoras com base na tabulação dos resultados, 2019.

Os resultados da busca nas bases de dados de periódicos foram mais restritos que aqueles oriundos do ENPEC, tendo em vista o uso do operador de busca $A N D^{1}$, que permitiu a identificação preliminar de trabalhos diretamente relacionados ao tema de interesse. Após leitura flutuante dos resumos e metodologias dos trabalhos de periódicos e do ENPEC selecionamos aqueles relacionados a iniciativas formativas na formação inicial e/ou continuada em disciplinas/eixo curriculares, cursos, grupo de pesquisa e programas/projetos desenvolvidos no Brasil, totalidade equivalente a 29 produções, descritas no quadro 2.

Quadro 2 - Trabalhos que constituíram o corpus de análise da pesquisa

\begin{tabular}{|c|c|c|c|c|}
\hline $\begin{array}{c}\text { Código de } \\
\text { Identificação }\end{array}$ & Autoria & $\begin{array}{c}\text { Periódico ou Edição do } \\
\text { ENPEC }\end{array}$ & Contexto da ação formativa & \\
\hline A01 & $\begin{array}{c}\text { Moreno Rodríguez e Del } \\
\text { Pino }(2019 b)\end{array}$ & $\begin{array}{c}\text { Investigações em Ensino } \\
\text { de Ciências }\end{array}$ & PIBID & \\
\hline A02 & Fernandes e Gouvêa (2019) & $\begin{array}{c}\text { Revista iberoamericana } \\
\text { de ciencia, tecnología y } \\
\text { sociedad }\end{array}$ & OBEDUC & \\
\hline $\mathrm{A} 03$ & Ritter e Maldaner (2015) & Práxis \& Saber & Disciplina de estágio & \\
\hline A04 & Geremias et al. (2016) & $\begin{array}{c}\text { Revista Iberoamericana } \\
\text { de Educación }\end{array}$ & OBEDUC & \\
\hline A05 & Trindade Souza et al. (2016) & Amazônia & Disciplina pedagógica & \\
\hline A06 & Silva e Marcondes (2015) & Ciência e Educação & Curso de formação & \\
\hline E01 & $\begin{array}{l}\text { Marques, Halmenschlager e } \\
\text { Wagner (2015) }\end{array}$ & $\mathrm{X}$ ENPEC & PIBID & \\
\hline E02 & Assai e Arrigo (2015) & X ENPEC & Disciplina pedagógica & \\
\hline E03 & Vacheski e Júnior(2015) & X ENPEC & Disciplina de estágio & \\
\hline E04 & Barcelos et al. (2015) & $\mathrm{X}$ ENPEC & $\begin{array}{c}\text { Projeto de Iniciação à docência } \\
\text { Práticas Motivadoras }\end{array}$ & \\
\hline E05 & $\begin{array}{c}\text { Binatto, Santos e Teixeira } \\
(2015)\end{array}$ & $X$ ENPEC & Disciplina com estágio & \\
\hline E06 & Lourencetti et al. (2017) & XI ENPEC & PIBID & \\
\hline E07 & Bezerra e Amaral (2017) & XI ENPEC & Disciplina pedagógica & \\
\hline E08 & Galieta e Dorvillé (2017) & XI ENPEC & Disciplina pedagógica & \\
\hline E09 & Selli Deconto, Cavalcanti e & XI ENPEC & Disciplina pedagógica & \\
\hline
\end{tabular}

\footnotetext{
${ }^{1}$ AND é um operador booleano que restringe os resultados das buscas em bases de dados e identifica trabalhos
} que tratam sobre duas temáticas de interesse. Para mais informações consultar Pizzani et al. (2012). 
Revista de Educação, Ciência e Tecnologia

\begin{tabular}{|c|c|c|c|}
\hline & Ostermann (2017) & & \\
\hline E10 & Fernandes e Strieder (2017) & XI ENPEC & OBEDUC \\
\hline E11 & Lima e Teixeira (2017) & XI ENPEC & Disciplina de conhecimento específico \\
\hline E12 & Nunes e Gonçalves (2017) & XI ENPEC & Eixo temático \\
\hline $\begin{array}{c}\text { Código de } \\
\text { Identificação }\end{array}$ & Autoria & $\begin{array}{c}\text { Periódico ou Edição do } \\
\text { ENPEC }\end{array}$ & Contexto da ação formativa \\
\hline E13 & Silveira e Gastal (2017) & XI ENPEC & Disciplina de estágio \\
\hline E14 & Leão e Koeppe (2019) & XII ENPEC & Disciplina pedagógica \\
\hline E15 & $\begin{array}{l}\text { Araújo-Queiroz, Santos e } \\
\text { Prudêncio (2019) }\end{array}$ & XII ENPEC & Disciplina pedagógica \\
\hline E16 & Vaciloto et al. (2019) & XII ENPEC & Curso de formação \\
\hline E17 & Lacerda e Strieder (2019) & XII ENPEC & PIBID \\
\hline E18 & Barros e Teixeira (2019) & XII ENPEC & Grupo de Pesquisa \\
\hline E19 & Fernandes et al. (2019) & XII ENPEC & Disciplina de conhecimento específico \\
\hline E20 & Richetti e Lambach (2019) & XII ENPEC & Disciplina de estágio \\
\hline E21 & Lopes e Gondim (2019) & XII ENPEC & Disciplina pedagógica \\
\hline E22 & $\begin{array}{l}\text { Fernandes, Machado e } \\
\text { Ibraim (2019) }\end{array}$ & XII ENPEC & Disciplina pedagógica \\
\hline E23 & Lima et al. (2019) & XII ENPEC & Disciplina pedagógica \\
\hline
\end{tabular}

Fonte: Elaborado pelas autoras com base na caracterização do corpus de análise, 2019.

Avaliamos os 29 manuscritos, corpus da pesquisa, com base na metodologia da Análise Textual Discursiva (ATD) (MORAES; GALIAZZI, 2006). Neste trabalho nossas unidades de significado equivalem aos trechos dos artigos selecionados na unitarização, momento da análise orientado pelo interesse em compreendermos as ações formativas CTS e a integração universidade-escola. Tais tópicos foram problematizados na construção do metatexto, última etapa da ATD, e a análise desenvolvida permitiu a caracterização e compreensão dos tipos de ações formativas, tendências quanto ao foco de formação, inicial ou continuada, modalidades de ensino discutidas, áreas de formação abordadas e intencionalidades das formações. Definimos códigos alfanuméricos de identificação, letra A para trabalhos de periódicos e letra E para publicações do ENPEC (Quadro 2), que serão utilizados na apresentação dos resultados.

\section{Ações formativas pautadas nos preceitos da Educação Ciência, Tecnologia e Sociedade}

\subsection{Caracterização das ações formativas CTS}

Neste mapeamento a definição do corpus de análise considerou pesquisas empíricas desenvolvidas a partir de ações formativas CTS inseridas em disciplinas, eixo curricular, grupo de pesquisa, cursos ou programas/projetos, que não estivessem limitadas a intervenções puramente investigativas. Observamos que 268 trabalhos (Quadro 1), 81\% da totalidade dos resultados, foi publicada nas atas do ENPEC, maior evento de pesquisa em educação em ciências, que evidencia a importância do evento para divulgação e discussão da temática, além disso, os trabalhos elaboram reflexões sobre o ensino CTS, apresentando e debatendo principalmente a elaboração de propostas de ensino. Caracterizar as ações formativas desenvolvidas no âmbito da Educação CTS foi uma das preocupações desse estudo, e assim, notamos que elas estão sendo desenvolvidas de duas formas principais: processos formativos vinculados a disciplinas na Formação Inicial e Projetos/Programas.

Os resultados apontam que os pesquisadores têm se empenhado em trabalhar as relações 
CTS nas disciplinas da formação inicial de professores (17 estudos), ações referentes ao ensino de Química, Física, Ciências Biológicas ou das Ciências de maneira geral (10 estudos), Estágios Supervisionados Obrigatórios (5 estudos) e disciplinas com ênfase nos conceitos científicos de Evolução Biológica e Química Orgânica (2 estudos). A pouca quantidade de ações inseridas em disciplinas de conhecimento científico aponta que o estudo CTS nesse contexto ainda é tímida, e, nesse sentido, sinalizamos que essa abordagem é importante e pode propiciar uma formação científica crítica quanto às concepções sobre Ciência, por meio da problematização dos conhecimentos científicos de Ciências Biológicas, Física e Química.

Revisões anteriores preocupadas com intervalos temporais inseridos no período de 2000 a 2017, evidenciaram que a maioria dos trabalhos focava na formação continuada de professores (STRIEDER et al., 2016; LACERDA; SANTOS; QUEIRÓS, 2017; PENHA; MACIEL, 2019). Na Figura 1, notamos que essa situação mudou e que a maior parte das ações agora acontecem em disciplinas da formação inicial de professores.

Figura 1 - Enfoques das ações formativas Ciência, Tecnologia e Sociedade

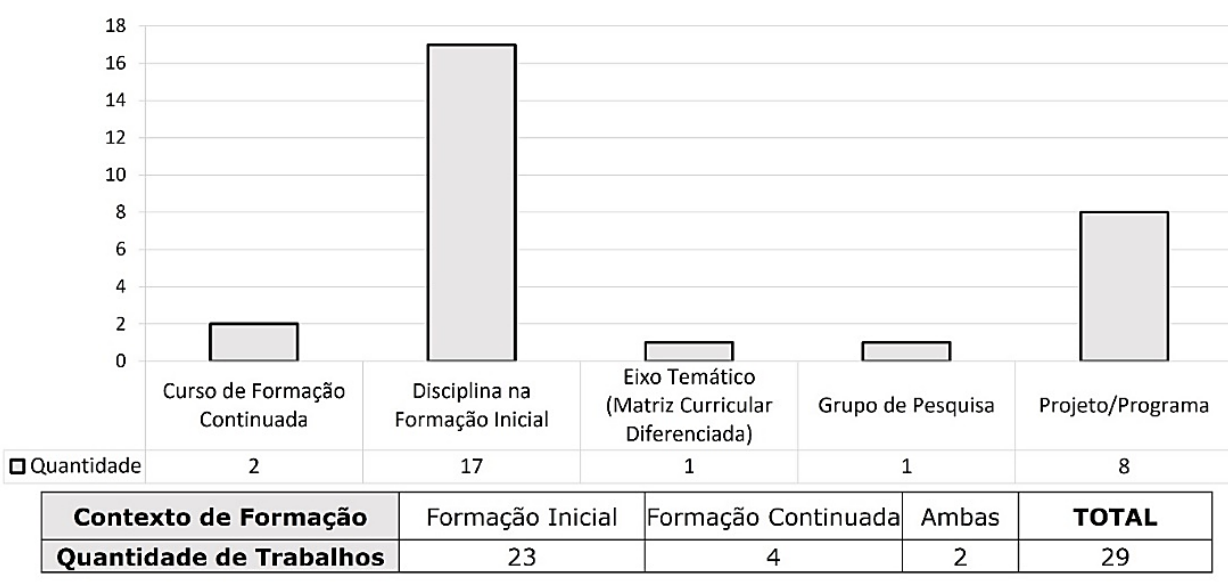

Fonte: Elaborada pelas autoras com base nos resultados da pesquisa, 2019.

Chama-nos a atenção o fato de apenas um trabalho apresentar ação formativa desenvolvida em grupo de pesquisa (BARROS; TEIXEIRA, 2019). De acordo com os autores dessa pesquisa, o objetivo foi mediar parcerias entre pesquisadores acadêmicos e professores da rede básica de ensino, possibilitando inclusive que os professores auxiliassem nas definições dos fenômenos de pesquisa. Essa possibilidade destaca a importância do envolvimento do professor da educação básica nas pesquisas a partir de discussões CTS, que podem ser importantes para a construção de uma identidade docente questionadora e crítica.

Para além dos tipos de ações formativas, observamos que a maior parte delas está acontecendo no âmbito da formação inicial de professores, por meio de disciplinas e programa/projetos. O enfoque nessa etapa formativa acontece em maior número nas iniciativas voltadas para formação de professores de Química e Ciências Biológicas (Figura 2), resultado semelhante ao apresentado por Strieder et al. (2016).

Figura 2 - Contexto e áreas do conhecimento enfatizadas nas formações CTS 


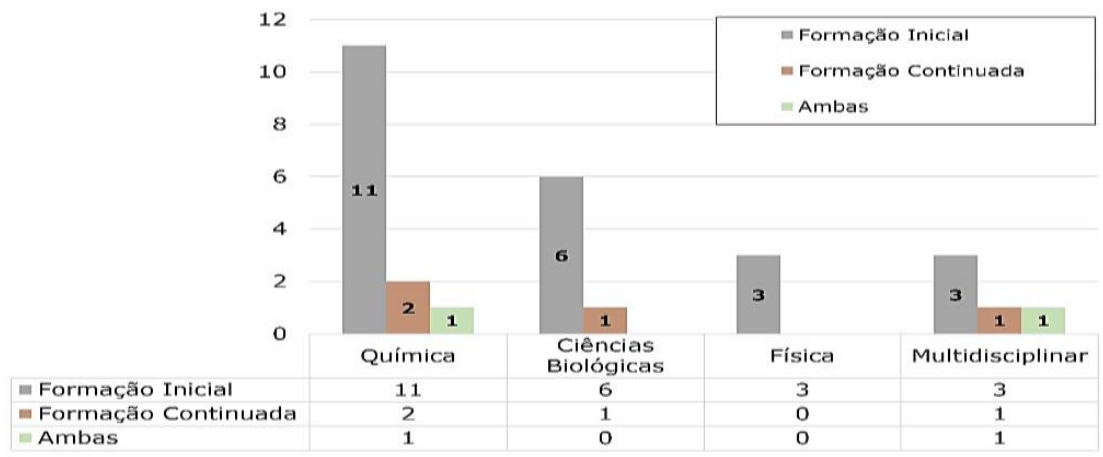

Fonte: Elaborada pelas autoras com base nos resultados da pesquisa, 2019.

A tendência de iniciativas formativas voltadas para formação inicial de professores diverge daquela apresentada por Strieder et al. (2016) em que a maior parte dos trabalhos tratavam sobre a formação continuada. E apesar de identificarmos ações vinculadas a programas como PIBID e OBEDUC, que conseguem envolver o licenciando em equipes diversificadas de trabalho, a preocupação maior é entender as contribuições das atividades formativas para os futuros professores. As interações entre universidade e escola nas ações formativas estudadas apresentam diferentes conformações. Nesses processos nem sempre é possível uma articulação entre estes dois espaços, no limite universidade-escola é constituída a comunidade fronteiriça em que o coletivo escolar e acadêmico interage (FIORENTINI, 2013), tais relações delimitam diferentes desenhos formativos nas ações formativas CTS (Figura 3).

Figura 3 - Relações cooperativas nas ações formativas CTS

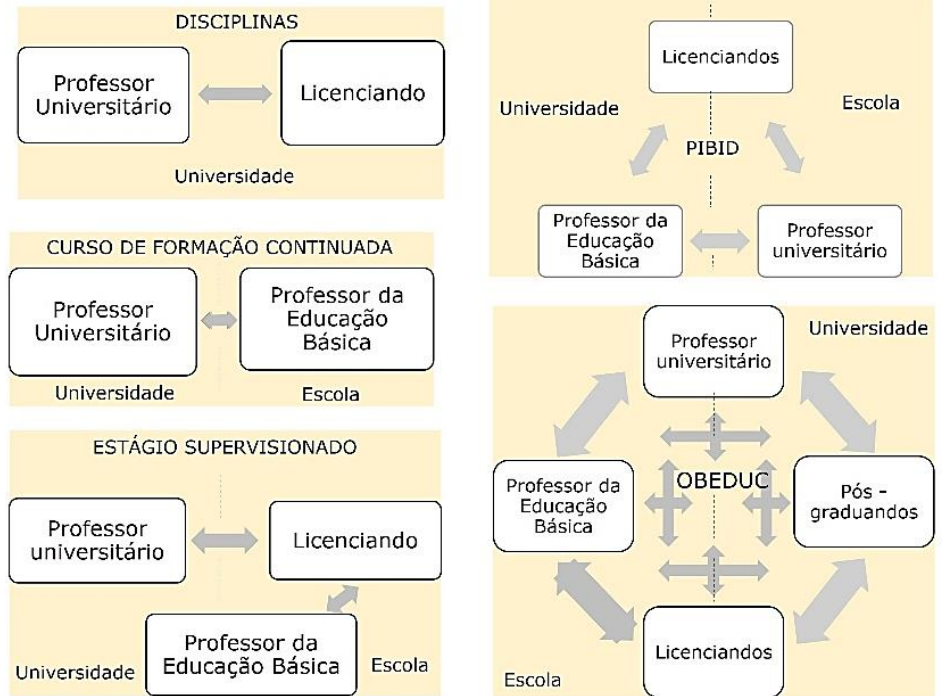

Fonte: Elaborada pelas autoras com base nos resultados da pesquisa, 2019.

Percebemos que algumas ações têm maior potencial de envolver diferentes agentes sociais e possibilitar a aproximação entre universidade e escola (Figura 3), mas não podemos encará-las de forma isolada e hierárquica. Acreditamos que essas ações necessitam estar articuladas, pois cada uma cumpre um papel formativo diferente, em conjunto podem proporcionar o desenvolvimento profissional dos professores da escola básica e universidade, além da construção de concepções CTS e didático-pedagógicas críticas.

Dentre os 29 estudos analisados, destacamos que 16 deles demonstraram preocupações com a prática educativa CTS, pois promoveram o planejamento e elaboração de materiais didáticos, planejamentos de sequências didáticas, planos de aula/planos de ensino, projetos e 
discussões sobre atividades de ensino desenvolvidas no contexto escolar. Muitas vezes essas produções foram o objeto de análise dos estudos, revelando possivelmente uma tentativa de aproximar as discussões CTS da prática educativa na educação básica. Apenas dois estudos concentram-se em preocupações sobre o contexto e entorno da comunidade escolar, enquanto 11 pesquisas concentram-se nas discussões construídas ao longo do processo formativo, com destaque para a compreensão das concepções dos professores sobre CTS.

Com relação às modalidades de ensino enfatizadas nos trabalhos, quinze estudos (52\%) estavam preocupados com a prática educativa no âmbito da educação básica de maneira geral, nove deles $(31 \%)$ discutiam a atuação do profissional no contexto do Ensino Médio, e apenas cinco (17\%) apresentaram inquietações voltadas para o Ensino Fundamental. A ênfase no Ensino Médio também foi observada na revisão de Strieder et al. (2016), assim como a menor quantidade de trabalhos com enfoque no Ensino Fundamental.

Apesar de as pesquisas analisadas estarem inseridas em processos formativos, nem todas incluem discussões de autores específicos da formação de professores. Essa é uma característica que necessita ser compreendida em outras investigações, a fim de entendermos quais fundamentos teóricos têm sustentado as discussões sobre a formação de professores no âmbito da Educação CTS. Outro ponto que merece atenção é a continuidade dessas ações formativas, tendo em vista a necessidade do desenvolvimento profissional contínuo (CRECCI; FIORENTINI, 2018), inclusive a partir da Educação CTS.

\subsection{As ações formativas desenvolvidas em disciplinas da Formação Inicial}

A Figura 3 apresenta as relações envolvidas nas formações de professores com viés CTS, desenvolvidas em diferentes universidades e escolas do Brasil. Aquelas que acontecem nas disciplinas das licenciaturas, por exemplo, envolvem principalmente professores universitários e futuros professores. É importante refletir que essas iniciativas estão preocupadas com mudanças das concepções de CT e com a prática educativa CTS.

Os processos formativos CTS nas disciplinas dos currículos de formação inicial de professores permitem a desconstrução de visões deturpadas e reducionistas sobre as relações CTS, além da reflexão sobre o que Delizoicov et al. (2002) denominam de senso comum pedagógico proveniente unicamente da prática, que pode ser equivocado e insuficiente para o enfrentamento das problemáticas de ensino e planejamento de práticas educativas CTS.

As ações desenvolvidas em disciplinas da licenciatura são limitadas, já que normalmente acontecem apenas no espaço universitário e nem sempre conseguem refletir sobre situações do espaço real da sala de aula, nesse aspecto as disciplinas de estágio se destacam, pois abrangem práticas no contexto escolar (ASSAI; BROIETTI; ARRUDA, 2018). Apesar de os estágios serem importantes para a articulação entre teoria didático-pedagógica e prática, não deveriam ser os únicos componentes curriculares com potencial para tais relações. Além disso, os estágios na atual configuração dos currículos de formação inicial de professores têm sofrido críticas devido à maneira como são encarados ou realizados, muitas vezes como componentes isolados e sem continuidade (TAUCHEN; DEVECHI; TREVISAN, 2014).

Nas ações dos estágios supervisionados com viés CTS presentes nos trabalhos analisados percebemos, por exemplo, preocupações quanto à relação teoria e prática:

[...] defendemos o desenvolvimento de propostas de estágios embasadas pelo Movimento CTS, por aliar teoria e prática no intuito de contribuir com o estabelecimento de espaços para problematizar as visões de C\&T, tanto dos futuros docentes, nos âmbitos de discussão na universidade, como entre os estudantes nas salas de aula (E05, p. 7). 
Apesar da potencialidade para "aliar teoria e prática" e firmar "espaços para problematizar as visões de C\&T" as pesquisas realizadas nos estágios supervisionados com abordagem CTS continuam focadas apenas nos licenciandos. Essa pode ser tanto uma característica relacionada aos interesses investigativos, quanto ao fato de os estágios não serem normalmente reconhecidos como ambiente coletivo de aprendizagem, dificultando a relação teórico-prática nesses espaços (ASSAI; BROIETTI; ARRUDA, 2018). A forma como os estágios são desenvolvidos têm fortalecido a dicotomia teórico-prática, já que uma é vinculada unicamente a universidade e a outra à escola (TAUCHEN; DEVECHI; TREVISAN, 2014). Assim, destacamos que estágios desenvolvidos a partir da Educação CTS surgem como possibilidade de enfrentamento a esse problema.

Não encontramos indícios de trabalhos CTS em disciplinas que integram a Prática como Componente Curricular (PCC), que em nossa compreensão e de outros pesquisadores (DE SOUZA NETO; PINTO DA SILVA, 2014), também permitem interações formativas importantes quando compreendidas como elemento integrativo e interdisciplinar, contribuindo para o desenvolvimento profissional. Mas, há diferentes configurações da PCC nas licenciaturas (BRITO, 2011), e algumas vezes seu potencial é negligenciado já que suas 400 horas obrigatórias muitas vezes se encontram pulverizadas nas demais disciplinas.

\subsection{Ações formativas CTS desenvolvidas em Programas/projetos}

O Programa Institucional de Bolsas de Iniciação à Docência (PIBID), o Programa Observatório da Educação (OBEDUC) e o Projeto de Iniciação à Docência (PID) Práticas Motivadoras demonstraram potencial para construção de espaços permeados pela interação profissional entre formadores universitários, licenciandos, pós-graduandos e professores da educação básica, e de acordo com Tauchen, Devechi e Trevisan (2014) são componentes capazes de aproximar universidade e escola. Apesar de o PIBID (4 estudos), OBEDUC (3 estudos) e PID (1 estudo) trabalharem com diferentes agentes sociais do contexto educacional, na maioria dos trabalhos a ênfase da pesquisa também continua nos licenciandos, e não nos demais atores. O Programa Residência Pedagógica ${ }^{2}$, foi criado recentemente e talvez por isso mesmo não apareça nos resultados dessa pesquisa. Consideramos, no entanto, que futuras investigações poderão mostrar seu potencial como espaço formativo para o desenvolvimento de práticas docentes aliadas a Educação CTS.

Como defendemos anteriormente, o PIBID e OBEDUC promovem experiências compartilhadas entre diferentes profissionais, permitindo uma dinâmica de trabalho mediada pela construção coletiva. Nos trabalhos analisados há problematizações sobre a prática dos licenciandos nesses contextos, aspecto relevante para construções e reconstruções de saberes profissionais, além de reflexões a respeito da prática docente. Neste sentido, é importante destacar o lugar que ocupam as ações formativas CTS desenvolvidas nesses Programas, como também a importância do planejamento coletivo:

[...] a formação inicial ou continuada de professores na perspectiva CTS envolve o desenvolvimento de um conjunto amplo de habilidades, competências, conhecimentos e atitudes. Para isso, requer situações formativas pautadas principalmente na reflexão crítica individual e coletiva sobre a docência, na pesquisa e prática interdisciplinar, na

\footnotetext{
2 O PIBID integra a política de formação de professores no Brasil, promovendo a inserção de licenciandos na rede pública de ensino. O OBEDUC, criado em 2006 e finalizado em 2017, foi um Programa de apoio à formação de professores da educação básica brasileira. E o Programa Residência Pedagógica, criado em 2018, também é uma iniciativa vinculada à política de formação de professores que prevê a preparação para a futura prática docente. Para mais informações consultar (BRASIL, 2006, 2016, 2018).
} 
contextualização dos conhecimentos e no enfrentamento dos desafios para práticas curriculares transformadoras (E23, p. 6).

[...] foram discutidos vários estudos sobre CTS e interdisciplinaridade, além de reflexões sobre a inserção de propostas dessa natureza nos currículos escolares. Além disso, foram elaboradas e desenvolvidas várias propostas de ensino (E10, p. 4).

[...] o professor deixa de ser visto como agente isolado e individualista, para ser considerado parte estruturante de uma equipe de trabalho (A01, p. 10).

Compreendemos que o desenvolvimento de formações CTS em Programas de iniciação à docência têm possibilitado, por exemplo, o rompimento de uma das constantes da docência, o isolamento do professor (MARCELO GARCÍA; VAILLANT, 2011), por meio da coletividade no trabalho dos educadores. Logo, as ações formativas desenvolvidas nesses espaços podem ser apontadas como modelos de aprendizagens que precisam ser mantidos.

Tauchen, Devechi e Trevisan (2014) sinalizam para a importância desses Programas na consolidação da comunicação entre universidade e escola. Além disso, salientamos que o planejamento conjunto proporciona o olhar para as demandas da escola, ignoradas com frequência, enquanto o planejamento cooperativo de práticas CTS demonstra a preocupação com a transposição dos preceitos da Educação CTS para a sala de aula, permitindo a construção de propostas de ensino mais próximas da realidade escolar, ao mesmo tempo que:

“[...] coloca como princípios básicos do seu desenvolvimento a promoção da interdisciplinaridade e a participação dos alunos. Isso é um desafio não apenas para os professores, mas também para toda a comunidade acadêmica e o próprio sistema educacional" (A01, p. 105).

Nesse processo coletivo a interdisciplinaridade defendida pela Educação CTS prevê o desenvolvimento de práticas a partir de problematizações que integrem diferentes áreas do conhecimento, e não apenas as científicas. Essa articulação no contexto da formação do professor ganha novas nuances, tendo em vista as interações multidisciplinares que podem atingir o patamar interdisciplinar nas aprendizagens profissionais destes processos formativos. A integração do espaço acadêmico com o escolar, em programas como o PIBID, possibilita:

[...] a "interposição profissional", a qual fundamenta-se na importância de possibilitar que cada professor construa sua posição como profissional a partir do contato direto com o ambiente escolar [...] promove a interação entre professores de diversos níveis de experiência, pois contempla as potencialidades do trabalho coletivo e reconhece a função formadora dos professores das escolas (A01, p. 116).

O PIBID aliado à Educação CTS pode ser encarado como componente capaz de aproximar universidade-escola e problematizar questões importantes para o desenvolvimento profissional do professor. Na compreensão de Fiorentini (2013), podemos considerá-lo uma iniciativa limítrofe capaz de integrar demandas da escola e da academia.

\subsection{O ensino CTS e as dificuldades apontadas nas ações formativas}

Algumas questões dificultam e criam entraves para o desenvolvimento do ensino CTS vinculadas aos desafios de se ensinar ciências, comprometimento com a Alfabetização Científica e Tecnológica (Santos e Mortimer, 2001), e as necessárias aproximações entre as investigações do ensino de ciências e a realidade desse ensino nas escolas: 
Cabe destacar que, em geral, as escolas foram receptivas e apoiaram o desenvolvimento das propostas de ensino, mas o planejamento e execução ficaram centrados nos poucos professores que aderiram às propostas de ensino nas escolas, com restrita participação dos gestores e coordenadores pedagógicos (E10, p. 6).

Notamos aqui a importância da participação de toda escola, incluindo a gestão escolar, nas ações formativas. Afinal de contas, a compreensão do que está acontecendo pode promover o envolvimento e participação de maneira efetiva. Por isso a importância da articulação de ideias e objetivos, para o estabelecimento de uma relação estreita entre universidade e escola (TAUCHEN; DEVECHI; TREVISAN, 2014). Outro aspecto que não pode ser ignorado é a condição de trabalho do professor e o currículo da educação básica:

Situações como falta de horários, falta de orçamento, exigências de conteúdos, exigências administrativas ou simples falta de interesse impulsionam o professor a fechar a porta da sala de aula e a trabalhar de forma isolada e monótona (A01, p. 113).

[...] o cumprimento da grade curricular era uma das preocupações das professoras supervisoras. Houve, dessa forma, certa resistência com a possibilidade de alteração no currículo (E01, p. 4).

O trabalho do professor na educação básica expressa variáveis distintas, que quando não consideradas, afetam a aprendizagem docente. A longa jornada de trabalho, por exemplo, pode dificultar o desenvolvimento de novas práticas e concepções. Além disso, a rigidez do currículo escolar, focado apenas nos conceitos científicos, pode comprometer o trabalho das ações formativas CTS. Essa resistência manifestada pelos professores pode estar atrelada a dificuldade de encarar o currículo de forma flexível, inviabilizando o ensino interdisciplinar a partir de temas (SANTOS; MORTIMER, 2000, 2001). Tal problema também está articulado com a formação desses professores, que nem sempre abordam a autonomia docente e o questionamento das postulações dos currículos escolares.

As situações formativas CTS muitas vezes exigem atitudes e comportamentos para os quais os professores não foram formados, e permite o confronto de concepções pedagógicas:

[...] foi possível observar momentos de dificuldade para professores iniciantes se aterem ao diálogo aberto e democrático com os educandos. Há, portanto, a necessidade de professores e alunos serem formados para essa transformação em sala de aula, somente assim se realizaria a superação do modelo bancário a partir da proposta de uma educação dialógica e libertária (E06, p.7 e 8).

[...] o estudo sistemático de iniciativas balizadas em temas, a elaboração e a implementação de propostas de ensino pautadas nessa perspectiva têm trazido algumas contribuições para a formação docente dos acadêmicos, como novos entendimentos acerca do currículo escolar e do papel do professor no processo de construção do mesmo (E01, p. 8).

Por isso a importância da problematização das concepções de professores nas ações formativas CTS (MARTINS, 2002), para que compreendam a importância de perspectivas progressistas como a Educação CTS. Os dilemas didático-pedagógicos possibilitam construção e reconstrução de saberes da prática docente (CARVALHO; GIL-PÉREZ, 2011), por isso é importante investir na formação inicial e continuada desses profissionais. O discurso sobre a relevância desta perspectiva educacional é enfraquecido se não estiver acompanhado de 

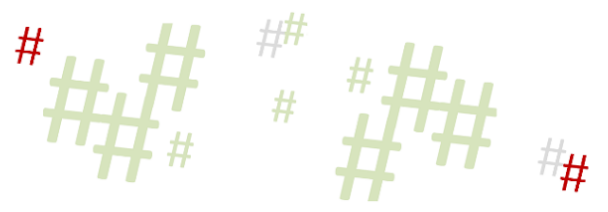

reflexões que compreendam o papel da formação inicial e continuada no processo de consolidação das práticas educativas CTS.

A carência de materiais didáticos também foi apontada como limitante na elaboração de práticas educativas CTS junto a professores e/ou licenciandos, tendo em vista que muitas vezes são necessários suportes para o planejamento desse ensino. Esta deficiência também foi sinalizada por Martins (2002) e se constitui como obstáculo na transposição da Educação CTS para as salas de aula da Educação Básica. Esse é um problema preocupante, mas os materiais e recursos das aulas CTS não podem ser pensados como prescrições, uma vez que mesma proposta CTS pode ser reestruturada pelo professor a partir dos contextos e perfis dos estudantes. É possível lidar com essa problemática valorizando os estudos sobre materiais didáticos (SANTOS; VALE; SILVA, 2017), como aqueles produzidos por professores e futuros professores em processos formativos. Esses recursos necessitam ser divulgados, disponibilizados e problematizados no contexto escolar, para que o ensino CTS não fique reduzido e estagnado na ausência de propostas educativas.

Diante dessas barreiras, a academia precisa estar mais engajada na superação dos desafios presentes no contexto escolar, mas tal participação não deve se resumir a intervenções impositivas, é necessário que seja estabelecido um processo dialógico que considere os posicionamentos da universidade e da escola no cenário educacional (TAUCHEN; DEVECHI; TREVISAN, 2014). O diálogo universidade-escola configura-se como um desafio na esfera educacional, pois muitas vezes a academia se sobrepõe à escola, e este não é o tipo de relação que permitirá transformações nos sistemas educativos. Todos esses apontamentos revelam uma questão mais abrangente, a elaboração e manutenção de políticas educacionais que consigam enfrentar a crise educacional vigente: 'Lamentavelmente, as mudanças políticas também afetam projetos significativos como o PIBID, o qual, durante nosso trabalho, esteve propenso a sofrer iminentes mudanças estruturais que poderiam ter diminuído seu impacto e inclusive causar sua desaparição' (A01, p. 114).

A formação do professor a partir dos preceitos CTS é uma das formas para lidar com esse cenário, pois sua intenção é preparar profissionais autônomos e críticos diante das questões sociais, políticas, científicas e tecnológicas, que lutem pela valorização de sua profissão, participem do debate sobre o currículo de ciências, estejam envolvidos com a elaboração de materiais didáticos e reivindiquem processos formativos coerentes. Em síntese, olhar para o sistema educativo de maneira questionadora e assumir posicionamentos sobre o ensino de Ciência e Tecnologia na escola. As perspectivas educacionais progressistas como Educação CTS estão preocupadas com a atuação política do professor (SOUZA DE FREITAS; QUEIRÓS, 2019). Nesse sentido, a Educação CTS pode viabilizar o desenvolvimento de práticas educativas tanto que discutam, por exemplo, a não neutralidade da CT, quanto, a longo prazo, possibilitem uma cultura de participação social (ROSA; STRIEDER, 2019).

\section{Considerações finais}

A principal inquietação do trabalho abrange a compreensão das ações formativas CTS e reflexões sobre a integração universidade-escola. A partir dessa problemática nos propusemos a caracterizar os estudos empíricos a respeito da formação de professores a partir da Educação CTS, buscando entender esses processos.

Identificamos que a maioria das iniciativas correspondem a ações desenvolvidas em disciplinas da formação inicial de professores, principalmente de Química e Biologia, além de outras modalidades, que abordam principalmente a prática educativa na educação básica de 
maneira geral, e no Ensino Médio. Destacam-se as ações desenvolvidas no PIBID e OBEDUC, pois envolvem o trabalho coletivo com diferentes atores profissionais. Defendemos uma maior articulação universidade-escola, para tanto as ações formativas CTS devem ser compreendidas como uma rede articulada e continuada, desenvolvidas mediante a investigação e colaboração, aproximando teoria e prática, ultrapassando a reflexão e adotando posturas investigativas, a partir do desenvolvimento profissional contínuo de professores da Educação Básica e do Ensino Superior (CRECCI; FIORENTINI, 2018).

O desenvolvimento profissional do professor no âmbito da Educação CTS pode dialogar com o potencial formativo das comunidades de aprendizagem defendidas por Crecci e Fiorentini (2018). Apontamos a necessidade de estudos com ênfase em processos formativos colaborativos e com viés CTS, que constituam comunidades descentralizadas e que atendam as demandas de ambos locais (FIORENTINI, 2013), permitindo ações pensadas pela academia e pelas escolas, apesar de não ignorarmos que existem desafios envolvidos nesse processo, como por exemplo, a pouca participação da escola nessas discussões (BAROLLI; VILLANI, 2015).

Este trabalho aponta questões de pesquisa que podem (re)significar formações de professores a partir da Educação CTS, sinaliza a importância de considerar as disciplinas que integram a PCC, o Programa Residência Pedagógica e as disciplinas de conhecimento científico específico, nas licenciaturas, como espaços possíveis para o desenvolvimento de abordagens CTS. Além disso, defendemos que a atuação conjunta das instituições acadêmicas e escolares significa resistência às dificuldades sociais e educacionais enfrentadas, preparando profissionais críticos e engajados na luta por mudanças na Educação.

\section{Agradecimentos}

Agradecemos à Coordenação de Aperfeiçoamento de Pessoal de Nível Superior (CAPES) e à Fundação de Amparo à Pesquisa do Estado da Bahia (Fapesb) pelo apoio e incentivo à pesquisa.

\section{Referências}

AIKENHEAD, G. S. What is STS science teaching? In: SOLOMON, J.; AIKENHEAD, G. (Ed.). STS education: International perspectives on reform. New York: Teachers College Press, 1994. p. 47-59.

AIKENHEAD, G. S.; RYAN, A. G. The Development of a New Instrument: 'Views on Science-Technology_Society' (VOSTS). Science Education, v. 76, n. 5, p. 477-491, set. 1992. Disponível em: <http://doi.wiley.com/10.1002/sce.3730760503>. Acesso em: 14 set. 2019.

ALONSO, Á. V.; ACEVEDO DÍAZ, J. A.; MANASSERO MAS, M. A. Aplicación del cuestionario de opiniones CTS con una nueva metodología en la evaluación de un curso de formación CTS del profesorado. Tarbiya, revista de Investigación e Innovación Educativa, n. 37, p. 31-65, 2006. Disponível em: 〈https://revistas.uam.es/tarbiya/article/view/7216>. Acesso em: 14 set. 2019.

ARAÚJO-QUEIROZ, M. B.; SANTOS, D. W. da C.; PRUDÊNCIO, C. A. V. As relações CTS e a formação cidadã no ensino de Biologia: articulações necessárias para a formação de professores. In: Encontro Nacional de Pesquisa em Educação em Ciências, Natal, RN. Anais 
do XII ENPEC. Natal, RN: 2019.

ASSAI, N. D. de S.; ARRIGO, V. CTS no ensino de Química: as concepções de licenciandos. In: Encontro Nacional de Pesquisa em Educação em Ciências, Águas de Lindóia, São Paulo. Anais do X ENPEC. Aguás de Lindóia, São Paulo: ABRAPEC, 2015.

ASSAI, N. D. de S.; BROIETTI, F. C. D.; ARRUDA, S. de M. O Estágio Supervisionado na formação inicial de professores: estado da arte das pesquisas nacionais da área de ensino de ciências. Educação em Revista, v. 34, p. 1-44, 2018. Disponível em:

<http://www.scielo.br/scielo.php?script=sci_abstract\&pid=S0102-

$46982018000100189 \& \operatorname{lng}=$ pt\&nrm=iso $>$. Acesso em: 14 set. 2019.

AULER, D. Interações entre ciência-tecnologia-sociedade no contexto da formação de professores de ciências. Tese (Doutorado em Educação). Centro de Educação. Universidade Federal de Santa Catarina, Florianópolis, SC, 2002.

AULER, D. Alfabetização científico-tecnológica: um novo "paradigma"? Ens. Pesqui. Educ. Ciênc. (Belo Horizonte), v. 5, n. 1, p. 68-83, jun. 2003. Disponível em:

<http://www.scielo.br/scielo.php?script=sci_arttext\&pid=S1983-

$21172003000100068 \& \operatorname{lng}=$ pt\&tlng=pt>. Acesso em: 14 set. 2019.

AULER, D.; DELIZOICOV, D. Ciência-Tecnologia-Sociedade: relações estabelecidas por professores de ciências. Revista electrónica de enseñanza de las ciencias, v. 5, n. 2, p. 337 355, 2006. Disponível em: <http://reec.uvigo.es/volumenes/volumen5/ART8_Vol5_N2.pdf>. Acesso em: 14 set. 2019.

BARCELOS, A. S. et al. A imersão de licenciandos em aulas por temas. In: Encontro Nacional de Pesquisa em Educação em Ciências, Águas de Lindóia, SP. Anais do X ENPEC. Águas de Lindóia, SP: ABRAPEC, 2015.

BAROLLI, E.; VILLANI, A. A formação de professores de Ciências no Brasil como campo de disputas. Revista Exitus, v. 5, n. 1, p. 72-90, 2015. Disponível em:

<http://www.ufopa.edu.br/portaldeperiodicos/index.php/revistaexitus/article/view/92>. Acesso em: 16 set. 2019.

BARROS, R. V.; TEIXEIRA, P. M. M. Educação CTS na formação continuada de professores: reflexões sobre ensino de ciências e cidadania. In: Encontro Nacional de Pesquisa em Educação em Ciências, Natal, RN. Anais do XII ENPEC. Natal, RN: ABRAPEC, 2019.

BEZERRA, B. H. da S.; AMARAL, E. M. R. do. Análise da Dinâmica Discursiva sobre as Interações em Ciência, Tecnologia e Sociedade (CTS) no Contexto da Licenciatura em Química. In: Encontro Nacional de Pesquisa em Educação em Ciências, Florianópolis, SC. Anais do XI ENPEC. Florianópolis, SC: ABRAPEC, 2017.

BINATTO, P. F.; SANTOS, A. C. D.; TEIXEIRA, P. M. M. Problematização de construções históricas sobre a Ciência e a Tecnologia por licenciandos: análise a partir de uma proposta de estágio. In: Encontro Nacional de Pesquisa em Educação em Ciências, Águas de Lindóia, SP. Anais do X ENPEC. Águas de Lindóia, SP: ABRAPEC, 2015.

BRITO, L. D. A configuração da "prática como componente curricular" nos cursos de licenciatura em Ciências Biológicas das Universidades Estaduais da Bahia. 2011. 
Doutorado em Ciências Humanas, Programa de Pós-Graduação em Educação. Universidade Federal de São Carlos, São Paulo - SP, 2011.

CARVALHO, A. M. P. de; GIL-PÉREZ, D. Formação de professores de ciências: tendências e inovações. Coleção Questões da nossa época. 10. ed. São Paulo: Cortez, 2011.

CEREZO, J. L. Ciencia, tecnología y sociedad: el estado de la cuestión en Europa y Estados Unidos. Revista Iberoamericana de educación, v. 18, p. 41-68, 1998. Disponível em: <https://rieoei.org/historico/oeivirt/rie18a02.htm>. Acesso em: 10 out. 2019.

CRECCI, V. M.; FIORENTINI, D. Desenvolvimento profissional em comunidades de aprendizagem docentes. Educação em Revista, v. 34, p. 1-20, jan. 2018. Disponível em: $<$ http://www.scielo.br/scielo.php?script=sci_arttext\&pid=S0102$46982018000100111 \& \operatorname{lng}=$ pt\&tlng=pt $>$. Acesso em: 11 set. 2019.

DE SOUZA NETO, S.; PINTO DA SILVA, V. Prática como Componente Curricular: questões e reflexões. Revista Diálogo Educacional, v. 14, n. 43, p. 889, 12 jul. 2014. Disponível em: <https://periodicos.pucpr.br/index.php/dialogoeducacional/article/view/2029>. Acesso em: 28 nov. 2019.

DELIZOICOV, D. et al. Ensino de ciências: fundamentos e métodos. São Paulo: Cortez Editora, 2002.

FERNANDES, C. G. et al. Estudo de Caso como Estratégia para Desenvolver o Pensamento Crítico em Licenciandos em Química Case Study as strategies to develop Critical Thinking in undergraduate students of Chemistry Degree. In: Encontro Nacional de Pesquisa em Educação em Ciências, Natal, RN. Anais do XII ENPEC. Natal, RN: ABRAPEC, 2019.

FERNANDES, J. P.; GOUVÊA, G. A perspectiva CTS e a formação docente na visão de professores da educação básica brasileira. Revista Iberoamericana de Ciencia, Tecnología y Sociedad, v. 14, n. 41, p. 41-69, 2019. Disponível em:

<http://www.revistacts.net/files/Volumen_14_Numero_41/02Fernandes.pdf>. Acesso em: 16 nov. 2019.

FERNANDES, R. F.; MACHADO, P. F. L.; IBRAIM, S. de S. Propostas de ensino CTS: contribuições para formação inicial de professores de Química. In: Encontro Nacional de Pesquisa em Educação em Ciências, Natal, RN. Anais do XII ENPEC. Natal, RN: ABRAPEC, 2019.

FERNANDES, R. F.; STRIEDER, R. B. Dificuldades enfrentadas por professores na implementação de propostas CTS. In: Encontro Nacional de Pesquisa em Educação em Ciências, Florianópolis, SC. Anais do XI ENPEC. Florianópolis, SC: ABRAPEC, 2017.

FIORENTINI, D. Learning and Professional Development of the Mathematics Teacher in Research Communities. Sisyphus, v. 1, n. 3, p. 151-181, 2013. Disponível em: <https://revistas.rcaap.pt/sisyphus/article/view/3710>. Acesso em: 15 nov. 2019.

GALIETA, T.; DORVILLÉ, L. F. M. Análise de sequências didáticas produzidas por licenciandos no contexto de uma disciplina "Ciência, Tecnologia e Sociedade". In: Encontro Nacional de Pesquisa em Educação em Ciências, Florianópolis, SC. Anais do XI ENPEC. 
Florianópolis, SC: ABRAPEC, 2017.

GEREMIAS, B. M. et al. Cuestiones sociotecnológicas en la formación de profesores de ciencias: una perspectiva discursiva. Revista Iberoamericana de Educación, v. 70, n. 1, p. 115-128, 2016. Disponível em: <https://rieoei.org/RIE/article/view/76>. Acesso em: 3 out. 2019.

LACERDA, N. O. S.; SANTOS, W. L. P. dos; QUEIRÓS, W. P. de. Um Panorama das pesquisas sobre formação de professores na perspectiva Ciência, Tecnologia, Sociedade (CTS). In: Encontro Nacional de Pesquisa em Educação em Ciências, Florianópolis. Anais do XI ENPEC. Florianópolis: ABRAPEC, 2017.

LACERDA, N. O. S.; STRIEDER, R. B. Contribuições da Educação CTS para o desenvolvimento da autonomia docente. In: Encontro Nacional de Pesquisa em Educação em Ciências, Natal, RN. Anais do XII ENPEC. Natal, RN: ABRAPEC, 2019.

LEÃO, M. F.; KOEPPE, C. He. B. Abordagem CTS e cidadania na Educação Escolar Indígena: considerações dos índios professores em formação. In: Encontro Nacional de Pesquisa em Educação em Ciências, Natal, RN. Anais do XII ENPEC. Natal, RN: ABRAPEC, 2019.

LIMA, M. R. De; TEIXEIRA, P. M. M. Enfoque CTS e o Ensino de Evolução: análise da articulação da tríade CTS em uma experiência didática. In: Encontro Nacional de Pesquisa em Educação em Ciências, Florianópolis, SC. Anais do XI ENPEC. Florianópolis, SC:

ABRAPEC, 2017.

LIMA, N. W. et al. Reiki no SUS e o Misticismo Quântico: Reflexões a partir do posicionamento de alunos de Licenciatura em uma aula de Física Quântica sob a perspectiva CTS. In: Encontro Nacional de Pesquisa em Educação em Ciências, Natal, RN. Anais do XII ENPEC. Natal, RN: ABRAPEC, 2019.

LOPES, E. A. de M.; GONDIM, M. S. da C. Projetos com orientação CTS: existe problematização ? In: Encontro Nacional de Pesquisa em Educação em Ciências, Natal, RN. Anais do XII ENPEC. Natal, RN: ABRAPEC, 2019.

LOURENCETTI, A. P. S. et al. Ação e reflexão na formação inicial de professores: análise de atividades do PIBID com alunos de Educação Básica. In: Encontro Nacional de Pesquisa em Educação em Ciências, Florianópolis, SC. Anais do XI ENPEC. Florianópolis, SC: ABRAPEC, 2017.

MARCELO GARCÍA, C.; VAILLANT, D. Desarrollo profesional docente: ¿Cómo se aprende a enseñar? 1. ed. Servilla, Espanha: Narceae Ediciones, 2011.

MARQUES, S. G.; HALMENSCHLAGER, K. R.; WAGNER, C. Abordagem de temas na formação inicial : a perspectiva CTS no âmbito do PIBID. In: Encontro Nacional de Pesquisa em Educação em Ciências, Anais do X ENPEC. ABRAPEC, 2015.

MARTINS, I. Problemas e perspectivas sobre a integração CTS no sistema educativo português. REEC: Revista electrónica de enseñanza de las ciencias, 2002. Disponível em: <https://dialnet.unirioja.es/servlet/articulo?codigo=1253615>. Acesso em: 29 set. 2019. 
MIRANDA, E. M. et al. Discutindo a visão de professores universitários sobre algumas das características dos cientistas. Enseñanza de las ciencias: revista de investigación y experiencias didácticas, n. Extra, p. 2775-2780, 2017. Disponível em: <https://www.raco.cat/index.php/Ensenanza/article/view/339718/430689>. Acesso em: 11 set. 2019.

MORAES, R.; GALIAZZI, M. do C. Análise textual discursiva: processo reconstrutivo de múltiplas faces. Ciência \& Educação (Bauru), v. 12, n. 1, p. 117-128, 2006. Disponível em: <http://www.scielo.br/pdf/ciedu/v12n1/08.pdf>. Acesso em: 1 out. 2019.

MORENO RODRÍGUEZ, A. S.; DEL PINO, J. C. Estudo da produção científica sobre o enfoque CTS em revistas brasileiras especializadas. Amazônia: Revista de Educação em Ciências e Matemáticas, v. 15, n. 33, p. 167, 2019a. Disponível em: $<$ https://periodicos.ufpa.br/index.php/revistaamazonia/article/view/6091/5611>. Acesso em: 20 out. 2019 a.

MORENO RODRÍGUEZ, A. S.; DEL PINO, J. C. O enfoque Ciência, Tecnologia e Sociedade (CTS) na reconstrução da identidade profissional docente. Investigações em Ensino de Ciências, v. 24, n. 2, p. 90, 28 ago. 2019b. Disponível em: <https://www.if.ufrgs.br/cref/ojs/index.php/ienci/article/view/1294>. Acesso em: 20 out. 2019 b.

MÜNCHEN, S.; ADAIME, M. B. Compreensões de licenciandos em química sobre as interrelações CTS a partir do questionário VOSTS. In: Encontro Nacional de Pesquisa em Educação em Ciências, Águas de Lindóia, SP. Anais do XII ENPEC. Águas de Lindóia, SP: ABRAPEC, 2019.

NUNES, C. de B.; GONÇALVES, T. V. O. No Território das ideias sobre Ciência e Tecnologia: relações ideacionais de professores em formação inicial para os anos iniciais escolares. In: Encontro Nacional de Pesquisa em Educação em Ciências, Florianópolis, SC. Anais do XI ENPEC. Florianópolis, SC: ABRAPEC, 2017.

PENHA, P. X. da; MACIEL, M. D. Mapeamento do enfoque CTS e os saberes docentes na formação de professores de ciências. Revista de Ensino de Ciências e Matemática, v. 10, n. 3, p. 148-167, 21 jun. 2019. Disponível em:

<http://revistapos.cruzeirodosul.edu.br/index.php/rencima/article/view/2134>. Acesso em: 15 set. 2019.

PIZZANI, L. et al. A arte da pesquisa bibliográfica na busca do conhecimento. RDBCI: Revista Digital de Biblioteconomia e Ciência da Informação, v. 10, n. 1, p. 53, 10 jul. 2012. Disponível em: <https://periodicos.sbu.unicamp.br/ojs/index.php/rdbci/article/view/1896>. Acesso em: 15 nov. 2019.

PRUDÊNCIO, C. A. V. Perspectiva CTS em estágios curriculares em espaços de divulgação científica: contributos para a formação inicial de professores de Ciências e Biologia. 2013. 150 f. Tese (Doutorado em Educação). Universidade Federal de São Carlos, Faculdade de Educação, São Carlos, 2013.

RICHETTI, G. P.; LAMBACH, M. O Estágio Supervisionado da Licenciatura em Química : reflexões entre o planejado e o realizado degree: reflections between the planned and the 
realized. In: Encontro Nacional de Pesquisa em Educação em Ciências, Natal, RN. Anais do XII ENPEC. Natal, RN: ABRAPEC, 2019.

RITTER, J.; MALDANER, O. A. CTS na Situação de Estudo: Desenvolvimento Curricular e Formação de Professores. Praxis \& Sabre, v. 6, n. 11, p. 195-214, 2015. Disponível em: <http://www.scielo.org.co/pdf/prasa/v6n11/v6n11a09.pdf>. Acesso em: 10 set. 2019.

ROSA, S. E. da; STRIEDER, R. B. Não Neutralidade da Ciência-Tecnologia: verbalizações necessárias para potencializar a constituição de uma cultura de participação. Linhas Críticas, v. 25, p. 124-149, 2019. Disponível em:

<https://periodicos.unb.br/index.php/linhascriticas/article/view/19701/20569>. Acesso em: 15 out. 2019.

SANTOS, M. dos et al. A perspectiva CTS na formação inicial de professores de Ciências e Biologia: o que dizem especialistas da área. Indagatio Didactica, v. 11, n. 2, p. 401-412, 2019. Disponível em: <https://proa.ua.pt/index.php/id/article/view/6193>. Acesso em: 10 nov. 2019.

SANTOS, R. C. S. dos; VALE, W. K. M. do; SILVA, S. A. da. Tendências das pesquisas em CTS na formação de professores de Ciências. In: Encontro Nacional de Pesquisa em Educação em Ciências, Florianópolis. Anais do XI ENPEC. Florianópolis: ABRAPEC, 2017.

SANTOS, W. L. P. dos; MORTIMER, E. F. Uma análise de pressupostos teóricos da abordagem C-T-S (Ciência - Tecnologia - Sociedade) no contexto da educação brasileira. Ensaio Pesquisa em Educação em Ciências (Belo Horizonte), v. 2, n. 2, p. 110-132, dez. 2000. Disponível em: <http://www.scielo.br/scielo.php?script=sci_arttext\&pid=S1983$21172000000200110 \& \operatorname{lng}=$ pt\&tlng=pt $>$. Acesso em: 10 set. 2019.

SANTOS, W. L. P. dos; MORTIMER, E. F. Tomada de decisão para ação social responsável no ensino de ciências. Ciência \& Educação (Bauru), v. 7, n. 1, p. 95-111, 2001. Disponível em: <http://www.scielo.br/scielo.php?script=sci_arttext\&pid=S1516-73132001000100007>. Acesso em: 10 set. 2019.

SELLI DECONTO, D. C.; CAVALCANTI, C. J. de H.; OSTERMANN, F. A perspectiva Ciência, Tecnologia e Sociedade na formação inicial de professores de física: estudando concepções a partir de uma análise bakhtiniana. Alexandria: Revista de Educação em Ciência e Tecnologia, v. 9, n. 2, p. 87-119, 24 nov. 2016. Disponível em: <https://periodicos.ufsc.br/index.php/alexandria/article/view/1982-5153.2016v9n2p87>. Acesso em: 15 set. 2019.

SELLI DECONTO, D. C.; CAVALCANTI, C. J. de H.; OSTERMANN, F. Análise de um episódio interativo entre estudantes de um curso de Licenciatura em Física sobre aspectos didático-pedagógicos do enfoque CTS. In: Encontro Nacional de Pesquisa em Educação em Ciências, Florianópolis, SC. Anais do XI ENPEC. Florianópolis, SC: ABRAPEC, 2017.

SILVA, E. L. da; MARCONDES, M. E. R. Materiais didáticos elaborados por professores de química na perspectiva CTS: uma análise das unidades produzidas e das reflexões dos autores. Ciência \& Educação (Bauru), v. 21, n. 1, p. 65-83, 2015. Disponível em: $<$ http://www.scielo.br/pdf/ciedu/v21n1/1516-7313-ciedu-21-01-0065.pdf >. Acesso em: 20 
set. 2019.

SILVEIRA, P. M. B.; GASTAL, M. L. de A. O cinema no ensino de ciências: compreensão de licenciandos em Ciências Biológicas sobre o CTS e o uso de filmes sob essa perspectiva. In: Encontro Nacional de Pesquisa em Educação em Ciências, Florianópolis, SC. Anais do XI ENPEC. Florianópolis, SC: ABRAPEC, 2017.

SOUZA DE FREITAS, W. P.; QUEIRÓS, W. P. de. O cenário das pesquisas de sobre formação de professores de ciências na perspectiva progressista. Investigações em Ensino de Ciências, v. 24, n. 1, p. 154, 30 abr. 2019. Disponível em:

<https://www.if.ufrgs.br/cref/ojs/index.php/ienci/article/view/1212>. Acesso em: 10 out. 2019.

STRIEDER, R. B. Abordagens CTS na educação científica no Brasil: sentidos e perspectivas. 2012. Tese (Doutorado em Ensino de Física) - Ensino de Ciências (Física, Química e Biologia). Universidade de São Paulo, São Paulo, 2012. Disponível em: <http://www.teses.usp.br/teses/disponiveis/81/81131/tde-13062012-112417/>. Acesso em: 4 set. 2019.

STRIEDER, R. B. et al. Educação CTS e Educação Ambiental: ações na formação de professores. Alexandria: Revista de Educação em Ciência e Tecnologia, v. 9, n. 1, p. 57-81, 25 maio 2016. Disponível em:

<https://periodicos.ufsc.br/index.php/alexandria/article/view/1982-5153.2016v9n1p57>. Acesso em: 14 set. 2019.

STRIEDER, R. B.; KAWAMURA, M. R. D. Educação CTS: parâmetros e propósitos brasileiros. Alexandria: Revista de Educação em Ciência e Tecnologia, v. 10, n. 1, p. 27, 30 maio 2017. Disponível em:

<https://periodicos.ufsc.br/index.php/alexandria/article/view/1982-5153.2017v10n1p27>. Acesso em: 15 set. 2019.

TAUCHEN, G.; DEVECHI, C. P. V.; TREVISAN, A. L. Interação universidade e escola: uma colaboração entre ações e discursos. Revista Diálogo Educacional, v. 14, n. 42, p. 369393, 12 jul. 2014. Disponível em:

<https://periodicos.pucpr.br/index.php/dialogoeducacional/article/view/6572>. Acesso em: 15 set. 2019.

TRINDADE SOUZA, J. R. da et al. Ilhas interdisciplinares de racionalidade no ensino de ciências: uma experiência didática no PARFOR na Ilha do Marajó, Pará, Brasil. Amazônia: Revista de Educação em Ciências e Matemáticas, v. 12, n. 24, p. 85-98, 31 jul. 2016. Disponível em: <https://periodicos.ufpa.br/index.php/revistaamazonia/article/view/3194>. Acesso em: 17 nov. 2019.

VACHESKI, G. M. O.; JÚNIOR, Á. L. O planejamento de uma Sequência Didática: relações entre o ensino clássico e o ensino CTS. In: Encontro Nacional de Pesquisa em Educação em Ciências, Águas de Lindóia, SP. Anais do X ENPEC. Águas de Lindóia, SP: ABRAPEC, 2015.

VACILOTO, N. C. N. et al. Contextualização e CTSA no Ensino de Química: compreensão e propostas de professores. In: Encontro Nacional de Pesquisa em Educação em Ciências, 
Natal, RN. Anais do XII ENPEC. Natal, RN: ABRAPEC, 2019.

Recebido em dezembro de 2019.

Aprovado em maio de 2020. 